\title{
Reducing sodium content in dry-cured pork loin. A novel process using water vapour permeable bags
}

\author{
Fuentes, A., Verdú, S., Fuentes, C., Grau, R., Barat, J.M.
}

CUINA group. Department of Food Technology. Universitat Politècnica de València, Valencia, Spain

*E-mail of the corresponding author: anfuelo@upvnet.upv.es

\begin{abstract}
The objective of the present study was to test the feasibility of a new saltingcuring process using water vapour permeable bags to obtain a reduced sodium dry-cured loin. The process was applied with and without partial substitution of sodium chloride by potassium chloride. The developed methodology allows to obtain a dry-cured pork loin with partial sodium substitution similar to the product without reduced sodium content, regarding to their physicochemical parameters, texture and colour. The results indicated that the new process allowed to obtain a cured meat product with $50 \%$ less sodium and similar characteristics than the traditional products.
\end{abstract}

Keywords: sodium replacement; water vapour permeable bags; dry-cured loin; salt content; physicochemical parameters . 


\section{Introduction}

Numerous studies have demonstrated that the dietary intake of sodium significantly influences blood pressure levels and contributes to an increased risk of coronary heart disease and strokes ${ }^{[1,2]}$. In industrialized countries, the sodium intake exceeds the nutritional recommendations; for these reasons, health national and international authorities have set targets for a reduction in the sodium consumed in the $\operatorname{diet}^{[3]}$. Studies reveal that the principle sources of sodium in the diet are processed foods. A common EU framework for salt reduction has been developed to reduce the salt intake at population level. In this sense, the EU framework will focus on a limited number of food categories, but which contribute largely to salt intake in the diet in many Member States. Certain food categories such as bread, meat products, cheeses and ready meals have been identified as being among the major contributors across the EU, and are therefore targets for salt reduction at EU level ${ }^{[4]}$. Manufacturers of dry-cured meat products are facing the challenge to lower the sodium content in their products ${ }^{[5,6]}$. In dry-cured meat products, sodium chloride is an essential ingredient which contributes to the water holding capacity, protein binding, colour, flavour and texture. Moreover, salt decreases water activity $\left(a_{w}\right)$, and this significantly affects the shelf-life of foodstuffs ${ }^{[7]}$. In addition to an overall bacteriostatic effect of salt, it can also cause a slight shift in the microbial flora toward slower growing, gram positive bacteria species that are less detrimental to product quality and require more time to reach spoilage levels. The partial replacement of sodium chloride by potassium chloride has been proposed as a possible strategy to reduce the sodium content of this type of products ${ }^{[8-11]} . \mathrm{KCl}$ is less expensive than other salt replacers, has similar properties as $\mathrm{NaCl}$, and also exhibits possible health benefits ${ }^{[12,13]}$. However, the addition of $\mathrm{KCl}$ is limited by its bitter and astringent taste demanding a careful choice of the level of substitution ${ }^{[12]}$. Gou et al. ${ }^{[14]}$ found that $\mathrm{NaCl}$ can be replaced by $\mathrm{KCl}$ up to $40 \%$ with only slightly affecting sensory properties in fermented sausages and dry-cured loin. In this sense, Armenteros et al..$^{[12]}$ further reported that substitutions of up to $50 \%$ by $\mathrm{KCl}$ are possible affecting neither sensory properties nor proteolysis and lipolysis phenomena in dry-cured loin. However, during processing the water transport is influenced if $\mathrm{KCl}$ is present leading to a decreased weight loss during salting.

The objective of the present study was to test the feasibility of a new salting-curing process using water vapour permeable bags to obtain a reduced sodium dry-cured loin. A novel salting-curing process using water vapour permeable bags was applied with and without partial substitution of sodium chloride by potassium chloride. 


\section{Materials and Methods}

\subsection{Experimental design}

The salting process was carried out with a thermodynamic control by placing a known amount of salt on the product surface and allowing it to dissolve and penetrate ${ }^{[16]}$. The amount of salt to be added to the loin was calculated considering a moisture and salt content in the final product similar to the comemercial dry-cured loin $\left(x_{\text {zib }}^{\rho}=0.06 \mathrm{~g} \mathrm{Cl} / \mathrm{g}\right.$ dry material and $\mathrm{x}_{\mathrm{f}}=0.47 \mathrm{~g} / \mathrm{g}(\mathrm{w} / \mathrm{w})$ ). Chloride amount, $\mathrm{M}_{\mathrm{Cl}}$ (g of chloride), added to each loin was individualy calculated according to Eq. (1) considering the initial weight of the loins, $\mathrm{M}_{0}(\mathrm{~g})$ :

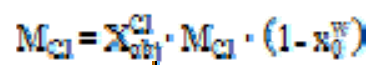

Finally, salt amount, $\mathrm{M}_{\text {salt }}(\mathrm{g})$, was calculated according to the salt composition $(100 \% \mathrm{NaCl}$ and $50 \% \mathrm{NaCl}: 50 \% \mathrm{KCl}$ ). Pork loins were covered with a layer of salt, and then, samples were vacuum-packed in the water vapour permeable bags. Initially, the salting-drying process was carried out at $90 \%$ relative humidity $(\mathrm{RH})$ and $3{ }^{\circ} \mathrm{C}$, and these conditions were modified during the process until reaching $65 \% \mathrm{RH}$ and $20^{\circ} \mathrm{C}$. Pork loins were kept in the drying chamber and periodically weighted until reaching a weight loss of $50 \%$.

\subsection{Analitical determinations}

\subsubsection{Physico-chemical analyses}

Moisture content was determined in accordance with AOAC methods $950.46^{[16]}$. Chloride content was determined after sample homogenisation in distilled water using an automatic chloride analyser (Sherwood Scientific Ltd., Cambridge, UK). The same extract was used to determine sodium and potassium contents by absorption spectrophotometry.The $\mathrm{pH}$ measurements were taken by a digital pH-meter (Crison Instruments, S.A., Barcelona, Spain) with a puncture electrode at five different locations on pork loin sample. Water activity $\left(a_{w}\right)$ was measured with a dew point hygrometer (Decagon Devices, Inc., Washington, USA). Texture profile analysis (TPA) was performed by use of a Texture Analyser TA.XT2 ${ }^{\circledR}$ (Stable Micro Systems, Surrey, UK) equipped with a load cell of 250 $\mathrm{N}$. Samples were obtained by cutting out parallelepiped pieces of $1 \times 1 \times 2,5 \mathrm{~cm}$ from the central part of each loin silce. For TPA analysis a flat-ended cylindrical plunger $(7.5 \mathrm{~cm}$ diameter) was pressed into the sample at a constant speed of $1 \mathrm{~mm} / \mathrm{s}$ until it reached $50 \%$ of the sample height. Force-distance curves were processed in order to obtain the texture parameters: hardness, cohesiveness, elasticity, chewiness and resilience. Colour determination was performed using a photocolorimeter (Minolta, Osaka, Japan) with a $10^{\circ}$ observer and illuminant D65. The colour system employed was CIE L*a*b*. 


\subsubsection{Sensory analysis}

Nine selected and trained assessors evaluated the dry-cured products using quantitative descriptive analaysis (QDA). Sensory attributes were grouped in visual appearance of the slice (color intensity and colour homogeneity), texture (hardness, adhesiveness and chewiness) and flavor (saltiness and cured flavour). Attributes were scored using an unstructured scale from 0 (very low) to 10 (very high).

\subsection{Statistical analysis}

One-way analysis of variance (ANOVA) was conducted for each physicochemical parameter and sensory attribute to establish significant differences between the typer of salt employed. The least significant difference (LSD) procedure was used to test for differences between averages at the 5\% significance level. Statistical treatment was performed using Statgraphics Centurion XVI (Manugistics Inc., Rockville, MD, USA).

\section{Results and discussion}

The average values of moisture, aw, and chloride, sodium and potassium content in pork loin samples salted with both type of salt are shown in Figure 1. As expected, the saltingdrying process significantly lowered the moisture and aw values, and chloride concentration increased compared with fresh meat. The procedure combining a controlled salting with the permeable bags was applied to reduce the impact of the different cations diffusivities duirng the salt uptake. In this procedure, the exact amount of salt to be absorbed by the loin is directly dosed and then packing forces the salt uptake, minimizing the differences in the $\mathrm{Na}$ and $\mathrm{K}$ transport. In order to determine mass transfer differences between salts, after processing pork loins were analyzed differentiating between the outer part and central part and the edges of said sections. This differentiation would also allow to detect crust formation. The crust formation poses serious problems for the certification of Serrano ham as a Guaranteed Traditional Speciality (ETG). According to ETG Serrano specifications, the moisture gradient between the outer part and the centre of the ham should not be higher than $12 \%{ }^{[17]}$.

Average moisture values of outer and central parts of the slices were $50.2 \%$ and $59.9 \%$ (w/w) for loins salted with $100 \% \mathrm{NaCl}$ and $60.3 \%$ and $51.1 \%(\mathrm{w} / \mathrm{w})$ for loins salted with $50 \% \mathrm{KCl}-50 \% \mathrm{NaCl}$. No significant differences were observed depending on the type of salt used. It should be noted that the moisture values in the center of the loins were higher than what would be desirable for this type of product. According to the quality standard of meat products, dry-cured loin ("embuchado lomo") should have a maximum moisture content of $55.0 \%{ }^{[18]}$. Taking into account the physico-chemical characteristics defined in this standard, it would be interesting to optimize the curing conditions with the aim of reducing the moisture content in the final product. 

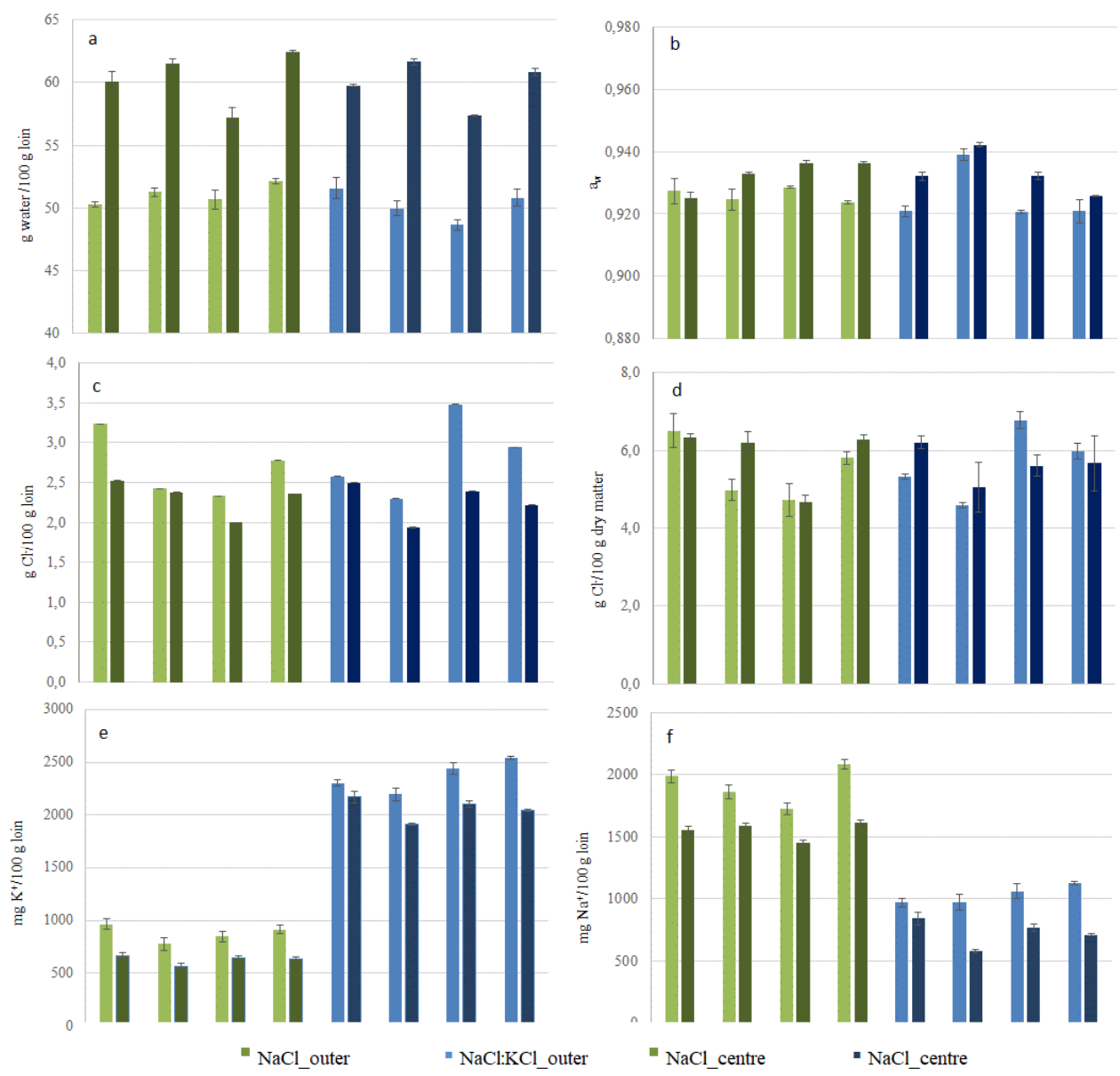

Figure 1. Moisture (a), $a_{w}(b)$, chloride content expressed in wet basis (c), chloride content expressed in dry basis (d), sodium content (e), potassium content ( $f$ ) of the dry-cured loin samples obtained by using $100 \% \mathrm{NaCl}$ and $50 \% \mathrm{NaCl}-50 \% \mathrm{KCl}$. Mean values \pm standard deviation $(\mathrm{n}=3)$.

Similar differences between slice areas were observed in chloride, potassium, and sodium content (Fig. 1). Solute concentration in the central part of the slice was significantly lower than in the outer part of the slice $(\mathrm{p}<0.001)$. The application of the new salting-curing process has made it possible to achieve a $50 \%$ reduction in sodium in the final product, as it had been established as a target. These results are especially interesting when compared with the alternatives salts in traditional processes, where it is not guaranteed that the final product will maintain this $\mathrm{Na}$ : $\mathrm{K}$ ratio, due to the differences in diffusivity of both salts. This ratio in the product with low sodium content was close to 1 (Na: K), being a nutritional advantage. 
Different studies have shown that sodium substitution by potassium could affect the mass transfer phenomena that occurs during the salting process. In this sense, different authors have reported that partial sodium replacement by potassium decreased water loss during processing ${ }^{[13,19]}$. This could be explained by the larger size of the $\mathrm{K}^{+}$ion, which would have more difficulty in penetrating inside the muscle. The salt uptake and water outflow occurs simultaneously, for this reason when replacement strategies are applied using traditional techniques final products had higher moisture values, longer curing processes are required or higher amounts of salt should be dosed to achieve an adequate $\mathrm{a}_{\mathrm{w}}$ value.

Dry-cured pork loin exhitited $\mathrm{pH}$ values ranged from 5.8 to 6.2 (data not shown) During processing, the $\mathrm{pH}$ values show a tendency to increase slightly, both in the surface and in the interior, throughout the process ${ }^{[20]}$. The type of salt did not affect any of the texture parameters evaluated (data not shown). These results agreed with those obtained in other studies where the effect of the partial sodium replacement by other salts in dry-cured meat products has been evaluated ${ }^{[5,13,12,15]}$. Aliño et al ${ }^{[15]}$ concluded that the partial substitution of $\mathrm{NaCl}$ by $\mathrm{KCl}$ in dry-cured pork loin did not affect texture of the product, except for a slight reduction of the elasticity when sodium substitution by potassium was higher than $50 \%$. Colour of samples was affected by the type of salt employed. In this sense, pork loins salted with $100 \% \mathrm{NaCl}$ showed values of $\mathrm{a}$ and $\mathrm{b}$ coordinates higher than samples salted with $50 \% \mathrm{KCl}-50 \% \mathrm{NaCl}$. Differences in lightness were not statistically significant (data not shown).

The overall scores marked by the assessors for the sensory attributes of the different evaluated samples are depicted in Fig. 4. No significant differences were recorded between samples for colour and texture attribute $(p>0.05)$, although the scores for taste and odour were slightly higher for pork loins salted with $100 \% \mathrm{NaCl}$.

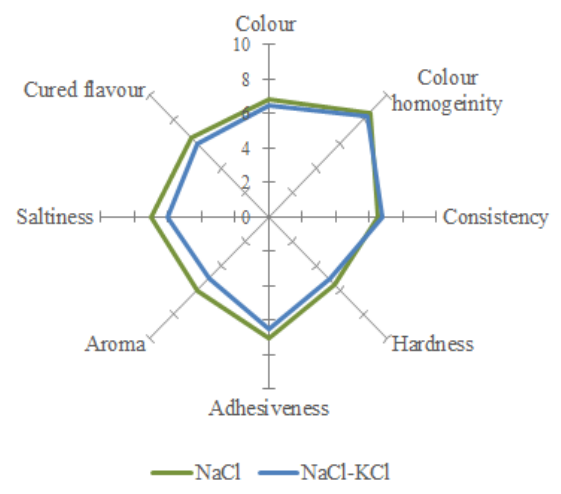

Fig. 2. Sensorial analysis of pork loin salted with $100 \% \mathrm{NaCl}$ and $50 \% \mathrm{NaCl}: 50 \% \mathrm{KCl}$ 


\section{Conclusions}

The developed methodology allows to obtain dry-cured products with partial replacement of sodium by potassium chloride with similar characteristics than products without reduced sodium content. The conditions of relative humidity and temperature used in this study have not been adequate to avoid the crusting of the pieces during the processing of cured loin. The replacement of $50 \%$ of $\mathrm{NaCl}$ by $\mathrm{KCl}$ had significant effect on some of the sensory atributes. The new process of controlled salting-curing using water vapor permeable bags allows to reduce the handling operations of the product and the use of salt, which is an advantage to help improve the hygienic quality of the product and reduce the environmental impact the generation of brine waste that is produced in these industries

\section{References}

[1] Inguglia, E.S.; Zhang, Z.; Tiwaria, B.K..; Kerry, J.P.; Burgess, C.M.. Salt reduction strategies in processed meat products - A review. Trends in Food Science \& Technology 2017, 59, 70-78.

[2] Ruusunen, M., Puolanne, E., 2005. Reducing sodium intake from meat products. Meat Science 70, 531-541.

[3] WHO/FAO, Diet, nutrition and the prevention of chronic diseases. WHO Technical Report Series 916, World Health Organization, Geneva, 2003.

[4] European Commision. Food and Health in Europe. Survey on Members States' Implemeentation of EU Salt Reduction Framework 2003. http://www.euro.who.int/document/E82161.pdf.

[5] Aliño, M.; Grau, R.; Fuentes, A.; Barat, J.M. Influence of low-sodium mixtures of salts on the post-salting stage of dy-cured ham process. Journal of Food Engineering 2010, 99, 198-203.

[6] Toldra, F., Reig, M. Innovations for healthier processed meats. Trends in Food Science \& Technology 2011, 22(9), 517-522.

[7] Toldrá, Fidel, and M. Barat. "Recent patents for sodium reduction in foods." Recent patents on food, nutrition \& agriculture 1.1 (2009): 80-86.

[8] Gelabert, J.; Gou, P.; Gerrero, L; Arnau, J. Effect of sodium chloride replacement on some characteristics of fermented sausages. Meat Science 2003, 65, 833-839.

[9] Ibañez, C.; Quitanilla, C.; Irigoyen, A.; Cid,C.; Astiasarán, I.; Bello, J. (1996). Dry fermented sausages elaborated with Lactobacillus plantarum- Staphylococcus carnosus. Part I: Effect of partial replacement of $\mathrm{NaCl}$ with $\mathrm{KCl}$ on the stability and the nitrosation process. Meat Science, 44:227-234 
[10] Wu, H.; Zhang, Y.; Long, M.; Tang, J.; Yu, W.; Wang, J.; Zhang, J. Proteolysis and sensoray properties of dry-cured bacon as affected by partial substitution of sodium chloride with potassium chloride. Meat Sciecne 2014, 96, 1325-1331.

[11] Aliño, M.; Grau, R.; Toldrá, F.; Blesa, E.; Pagán, M.J.; Barat,J.M. Influence of sodium replacement on physicochemical properties of dry-cured loin, Meat Science 2010, $83(3), 423-430$

[12] Armenteros, M.; Aristoy, M. C.; Barat, J.M.; Toldrá, F. Biochemical changes in drycured loins salted with partial replacements of $\mathrm{NaCl}$ by $\mathrm{KCl}$. Food Chemistry 2009, 117(4), 627-633.

[13] Aliño, M.; Grau, R.; Toldrá, F.; Blesa, E.; Pagán, M. J.; Barat, J. M. Influence of sodium replacement on physicochemical properties of dry-cured loin. Meat Science 2009, 83, 423-430.

[14] Gou, P.; Guerrero,L.; Gelabert, J.; Arnau, J. Potassium chloride, potassium lactate and glycine as sodium chloride substitutes in fermented sausages and in dry-cured pork loin. Meat Science 1996, , 42:37-48.

[15] Fuentes, A; Barat, J.M.; Fernández-Segovia, I.; Serra J.A. Study of sea bass (Dicentrarchus labrax L.) salting process: kinetic and thermodynamic control Food Control 2008, 19 (8), 757-763

[16] Official Methods of Analysis (16th ed.), Association of Official Analytical Chemists, Washington (1997)

[17] Fundación Jamón Serrano (1998). Pliego de condiciones para elaboración del Jamón Serrano.

[18] BOE, Boletín Oficial del Estado (2014). Real Decreto 474/2014, de 13 de junio, por el que se aprueba la norma de calidad de derivados cárnicos.

[19] Comaposada, J. Arnau, P. Gou, Sorption isotherms of salted minced pork and of lean surface of dry-cured hams at the end of the resting period using $\mathrm{KCl}$ as substitute for $\mathrm{NaCl}$. Meat Science 2007, 77(4), 643-648

[20] Arnau, J.; Serra, X.; Comaposada, J.; Gou, P. \& Garriga, M.Technologies to shorten the drying period of dry-cured meat products. Meat Science 2007, 77, 81-89. 